\title{
THE ROLE OF MOBILE APPLICATIONS IN THE CONSUMER EXPERIENCE AT MUSIC FESTIVALS
}

\author{
AMY LUXFORD AND JANET E. DICKINSON \\ School of Tourism, Bournemouth University, Poole, UK
}

\begin{abstract}
The ubiquitous capability of smartphones and their rapid uptake among music festival attendees indicates the potential for mobile applications as a tool within this environment. As a result, many organizers are choosing to develop festival-specific apps designed to enhance the user experience. Based on a review of festival apps and focus groups with festival attendees, this article analyzes the role of mobile apps in relation to festival consumer experiential needs. Analysis indicates a need for more consumer-focused app interfaces that pay close attention to the event anticipation experience, scheduling capabilities before and during the festival, and personalization options to enhance "presence.” At a practical level, mobile charging facilities are vital at festivals to enable app use.
\end{abstract}

Key words: Smartphone; Mobile applications; Festival; Consumer experience

Introduction

Given young people's adoption of mobile media, recent technological developments present both opportunities and challenges for festival managers (Allen, O’Toole, Harris, \& McDonnell, 2011; Pegg \& Patterson, 2010). Smartphone sales are projected to rise steadily in the next few years, providing event managers with a new and ubiquitous communication media - the smartphone app (Shapiro, 2011). This raises new questions about consumer needs and experiences within this context. There is currently limited literature on the consumer experience using apps and even less on the consumer experience of apps within an event context.
Smartphones and their associated apps are radically altering social interactions and increasingly mediate our consumption experiences. They are a powerful tool to help people make decisions on the go, fluidly maintaining network connectivity and enabling ad hoc meetings (Schwanen \& Kwan, 2008). The ability to correlate user activity patterns with their location provides contextual awareness and enables commercial organizations to target information to meet immediate user needs (Giaglis, Kourouthanassis, \& Tsamakos, 2003). This makes the smartphone a powerful tool in the festival context, which, given its youth market, has attracted much interest from mobile developers. Apps are potentially influential at all stages of the event experience, including before 
and after the event. Therefore, the main aim of this study is to analyze the emerging role of music festival mobile applications in the consumer experience.

\section{Literature Review}

\section{Consumer Technology Relations}

Smartphones have made a significant impact on the mobile phone market with 7 out of 10 adults in the UK owning a smartphone (Mintel Reports, 2014). Prior to widespread smartphone ownership, mobile technology was already making an impact at music festivals. For example, mobile ticketing introduced at V Festival in 2007 and near field communications, such as Bluetooth, had already shown some potential to deliver information to festival users ("Music Festivals to Expand," 2007). The advent of smartphone technology has enhanced and extended the available technology. For instance, radio-frequency identification (RFID) has enabled appropriately equipped users to make payments by mobile and access exclusive information ("Music Festivals to Expand,” 2007).

There is no definitive definition of a smartphone but they generally incorporate high-level computing capabilities, with typical talk and text functions, cameras, recording devices, and embed a range of sensors providing context awareness. Trends show rapid growth in ownership (mobiThinking, 2012) and a growing dependence on smartphones in people's day-to-day lives and during travel (Frommer's Unlimited, 2011). A number of studies have examined the relationship between the consumer and their smartphones, suggesting convenience and ubiquity are key drivers of use (Liu, 2010; Ting, Lim, \& Pantamacia, 2011; Wagner, 2011). Apps add to the usability of smartphones and have proved popular, with smartphone users spending more than 11 hours per month using apps (Korkmaz, Lee, \& Park, 2011), with 7 out of 10 users downloading at least one app per month (Mintel, 2011).

App is short for mobile application, which is tailor made software for mobile devices (Forsyth, 2011) that generally improves the user experience of mobile services. Apps offer unique opportunities because developers beyond the relative closed mobile phone market can design an app. This has led to a plethora of apps being developed for a wide range of purposes, including a variety of event contexts. Mid-2012 it is estimated that globally more than 1 million apps are available (United States Government Accountability Office, 2012). Since 2010, a growing number of apps have been developed to support users attending UK music festivals. In the context of corporate events, Thomas (2011) discusses how an app can benefit both event organizers and participants as it allows you to "communicate in real-time with participants and share or update information in seconds" (p. 14), while Dietz (2011) emphasizes the enhancement of attendees' experiences.

There are two varieties of apps: native apps and mobile web apps. Web apps are not technically apps, but a "mobile-optimized website" that users interact with via a Smartphone integrated browser and can be updated with an Internet connection (“App Happy," 2011). These sites are adapted to the smartphone's capabilities (e.g., touch screen and compressed screen resolution). Native apps, on the other hand, are stand-alone programs that can either be preinstalled on the phone or downloaded from an app store (Pessin, 2011). Native apps tend to work without an Internet connection as a lot of information is already incorporated into the app when downloaded. There are various pros and cons of native and web apps for a festival context (Table 1). Up until 2011 there appeared to be some user preference for mobile web (mobiThinking, 2012), though this is probably a reflection of the relatively limited quality and scope of apps available at the time. More recently, Fisher (2012) proposes that websites are fast becoming obsolete as consumers are favoring native apps; however, others question this. The latest version of HTML, HTML5, enables developers to build webbased apps that can run on any mobile platform, though it will be some time before this comes to dominate native apps (Business Insider, 2012).

\section{Space-Time and Network Sociality}

Since the emergence of mobile technology social scientists have been interested in how ubiquitous technology changes people's relationships with place (Wilken, 2008), time (Wajcman, 2008), other people (Sheller, 2004), and consumption practice (Buhalis \& Law, 2008). It is now well understood that mobiles alter space-time practices in 
Table 1

Pros and Cons of Native and Web Apps for Festivals

\begin{tabular}{|c|c|}
\hline Pros & Cons \\
\hline \multicolumn{2}{|l|}{ Native apps } \\
\hline Can use all device’s functions & Takes up phone memory \\
\hline $\begin{array}{l}\text { Typically loads and performs operations faster } \\
\text { than a web app }\end{array}$ & $\begin{array}{l}\text { All platforms need to be covered otherwise you could } \\
\text { isolate some attendees }\end{array}$ \\
\hline Can use push notifications & Difficult to maintain-updates need a good 3G signal \\
\hline Can run without an internet connection & or an internet connection to be downloaded \\
\hline Quick access & Have to have a Smartphone to use \\
\hline Can make accessing information easier & Hard to keep the quality the same throughout devices \\
\hline Can combine a variety of services & $\begin{array}{l}\text { The more information you put in the app the more } \\
\text { space it will take up on the phone }\end{array}$ \\
\hline \multicolumn{2}{|l|}{ Web apps } \\
\hline Can be built for all devices & Internet or good 3G signal essential for use \\
\hline Can use GPS & Cannot use push notifications \\
\hline $\begin{array}{l}\text { Does not need a Smartphone, just a phone with } \\
\text { an internet service }\end{array}$ & $\begin{array}{l}\text { Cannot use all device functions } \\
\text { Can be harder to use }\end{array}$ \\
\hline \multirow{2}{*}{\multicolumn{2}{|c|}{$\begin{array}{l}\text { Easy to reach-just use search engine or type } \\
\text { URL }\end{array}$}} \\
\hline & \\
\hline Does not take up phone memory & \\
\hline
\end{tabular}

Adapted from Murphy (2011).

the coordination of day-to-day life (Ling, 2004), allowing for increased spontaneity and fluidity in the organization of meetings with other people and the things we need (Campbell \& Kwak, 2011; Kwan, 2007; Line, Jain, \& Lyons, 2011; Ling, 2004; Neutens, Schwanen, \& Witloz, 2011). This will be true of the festival context, which is attracting the attention of computer scientists keen to provide services to a captive audience of young consumers (see, e.g., Driver \& Clarke, 2008). In a tourism setting, Dickinson et al. (2012) describe how the smartphone provides a new sociotechnical substrate that provides users with local knowledge in an unfamiliar environment. Such knowledge in a festival context might be unforeseen variations to the schedule, the fastest route back to your tent, or notification that an area is closed due to flooding. This immediate temporal and spatial knowledge can affect behavior, bringing benefits for both attendees and festival managers. Choices are changed by revelations based on information of immediate significance, personalized to individual users on the move. Wilken (2008) argues that far from disconnecting us from place, mobile technology in fact reconnects people to place and brings new understandings.

Similarly, the movement of social networking technology from the desktop computer to the smartphone has opened up new opportunities to exploit the interconnections between people, places, and the things people need. This has most obviously been exploited by marketing organizations (Buhalis \& Law, 2008), but there remains much untapped potential to seamlessly coordinate activities for social networks of users. Sheller (2004) suggests new kinds of fluid social spaces are emerging that are both public and private space. She argues that a network is too rigid to describe the messy and fluid movements of people between various physical and virtual space-times and social framings. As an alternative she draws on White's (1992) conceptualization of "publics" in which he uses a "gel" metaphor. Gel suggests more blurred boundaries of social interaction and also deals with the increasingly messy distinctions between local and global, public and private. "publics are special social spaces that allow for 'switching' between communicative contexts" (Sheller, 2004, p. 48). At a festival, attendees are now engaged in multiple social spaces, which include: the immediate social group with whom attendees arrived at the festival; wider social groups with whom they periodically interact through friends and opportunistic encounters; the entirety of festival attendees and organizers as a community; and friends in other spaces and times through mobile communication practices (e.g., text, phone call, e-mail, blogs, social network sites). 
Another significant development into which app developers are tapping is web 2.0. The power of social media is evident from the tourism field where user-generated feeds such as Facebook and Twitter frequently reveal travel problems ahead of national news broadcasts (Dickinson et al., 2012), and user reviews are exerting a powerful force on industry operations (Buhalis \& Law, 2008). Within the festival environment, where consumers are coproducers of the experience, the unique capacity of smartphones to connect users to other festival attendees, festival organizers, as well as other social settings, is providing a more relational experience. Wittel (2001) refers to this delocalized sociability conducted over distance and time as network sociality.

\section{Presence Theory}

In order to engage users apps require a degree of "presence." The concept of "presence" is derived from work on "social presence." This is the degree of human contact required for communication to be successful. Face-to-face communication is said to have the highest level of social presence, while a telephone call has less and written communication the least. For certain types of communication faceto-face meeting is vital, whereas other communication is adequate by letter (King \& Xia, 1997). These ideas have been translated to the "presence" concept in computer science, which has been explored extensively in the education field. Of more direct relevance to this study, work on mobile media by K. M. Lee, Yates, Clark, and El Sawy, (2010) describes presence as "the underlying phenomenon that explains why a certain combination of sensory and cognitive inputs leads to a more engaging user experience” (p. 273).

One of the means to improve user engagement is through services that connect with the user's location and identity (Smith \& Grubb, 2004). The benefits were recognized by Nokia Group (2002) as early as 2002 when they released a white paper focused entirely on presence. They explain that presence within an application is spatially aware and acknowledges the user's location leading to the recognition of subjects, which are of importance to the user and thus provides recommendations.

An appropriate degree of "presence" is vital for apps used in a festival context. Various app features can increase the feeling of presence, such as photo sharing capabilities (Counts \& Fellheimer, 2004). At a more conceptual level, presence research suggests a focus on sensory and functional needs (Venkatesh, Ramesh, \& Massey, 2003), interface and user attention span (Y. E. Lee \& Benbasat, 2004), and physical, social, and self-presence needs (K. M. Lee et al., 2010).

\section{Experience Literature}

Emotional and sensory stimulation lie at the heart of experiences (see, e.g., Carù \& Cova, 2003; Chang \& Horng, 2010; Jensen, 1999; Mossberg, 2007; Pine \& Gilmore, 1999), especially at music festivals. Festivals are also a space for individuals to perform an identity (Duffy, 2005) and enhance and make new social bonds (Matheson 2005). It instills a high level of "communitas"; that is, a "temporary state in which people are together, removed from ordinary life, so they have something very specific in common. Their experience should be unstructured, relative to the outside world, and egalitarian (everyone accepted as being equal)” (Getz, 2007, p. 178). In order to achieve these experiential objectives, festival attendees require a degree of control and mastery over the experience. For instance, Hemmerling (1997, cited in Bowdin, Allen, O’Toole, Harris, \& McDonnell, 2011) suggests event practicalities are key to attendee enjoyment, such as being able to see the program content or access food and other amenities. These are particularly important in the relatively crowded environment of a music festival. An appropriately structured environment that stimulates emotional engagement provides a "creative space" (Morgan, 2007) for the cocreation of unique value (Prahalad \& Ramaswamy, 2004). As Getz (2007) suggests, when reflecting on the leisure experience, "the experience should be accompanied by a sense of freedom, and of competence and control” (p. 172). This implies a degree of compromise. Some structure is required for participants to make immediate plans, yet spontaneity remains vitally important.

Festivals also take place over the course of several days, during which many participants reside on the festival site and thus become totally immersed in the festival context (Packer \& Ballantyne, 2005). Pine and Gilmore (1999) would define this as an "escapist experience” (p. 33) as attendees travel 
to a location, actively participate, and becoming fully immersed in the experience. This high level of immersion can result in the optimum experience state of "flow" (Csikszentmihalyi, 1990), though this again requires a degree of structure as the achievement of flow requires competence and control.

Clawson and Knetsch (1966) proposed five key stages in the development of a "multiphased" recreation experience: anticipation, travel to site, onsite activity, return travel, and recollection. A large number of event experiences nowadays incorporate technology during one or more of these phases. This presents both opportunities and challenges for events managers to involve and service event attendees (Allen et al., 2011, Bowdin et al., 2011). One of the challenges faced by events managers is the increasing expectations of the attendees as their everyday lived experiences involve sophisticated engagement with technological devices (Adema \& Roehl, 2010). It is therefore vital that technology enhances rather than detracts from the festival experience.

\section{Methodology}

Given the emergent nature of the topic and paucity of knowledge, an inductive research strategy was adopted with data drawn from a combination of primary and secondary sources. Secondary data consisted of UK music festival apps and their associated consumer reviews. Primary data were collected using focus groups comprising recent festival consumers.

In order to select a sample from the growing number of UK music festivals for the secondary data review, 20 recent music festival attendees were asked to identify the top 10 UK music festivals. This yielded nine apps for analysis (Table 2).

Given the lack of benchmarks for this topic, the apps were explored using inductive and qualitative content analysis to establish app content and performance categories (Table 3). This provided baseline knowledge of the current available features and issues with the apps that assisted in the design of a focus group protocol. There were limitations with this approach because the reviews did not take place at the festival; therefore, the conditions could not be replicated. It should also be noted that the apps were released in 2011 and technology rapidly dates in this market.
Table 2

Top UK Music Festivals

\begin{tabular}{|c|c|}
\hline Festival & Comments \\
\hline $\begin{array}{l}\text { Reading } \\
\text { Leeds } \\
\text { Glastonbury } \\
\text { Download } \\
\text { V Fest } \\
\text { Bestival }\end{array}$ & $\begin{array}{l}\text { Reading and Leeds are the same concert } \\
\text { in different locations }\end{array}$ \\
\hline $\begin{array}{l}\text { Creamfields } \\
\text { Isle of Wight } \\
\mathrm{T} \text { in the Park } \\
\text { Sonisphere }\end{array}$ & $\begin{array}{l}\text { No app available at the time of the study, } \\
\text { though app released } 2012\end{array}$ \\
\hline
\end{tabular}

Following this preliminary categorization process, reviews posted by users in app stores and official festival forums were thematically explored to provide more understanding of consumer issues outside of the researcher-mediated environment. The official forums were chosen as these are used by the targeted festival attendees and "self-revelation of private thoughts, experiences, and emotions is exceptionally widespread on the Internet, from personal blogs to online forums" (Jiang, Bazarova, \& Hancock, 2010, p. 59). Using app stores to ascertain information, though useful, must be reviewed with caution. Although the app stores provide guidelines, illegitimate reviews are hard to identify and may

Table 3

App Content and Performance Categories

\begin{tabular}{|c|c|}
\hline Category & Comments \\
\hline Platform used & For example, Android, iPhone \\
\hline GPS services offered & Location on map \\
\hline Personalization & $\begin{array}{l}\text { For example, creation of a } \\
\text { personal festival schedule }\end{array}$ \\
\hline One way/two way & $\begin{array}{l}\text { Whether you upload things } \\
\text { alongside others or whether } \\
\text { only the app provider can } \\
\text { upload material }\end{array}$ \\
\hline Connection requirements & $\begin{array}{l}\text { Does the app work without a } \\
\text { signal? }\end{array}$ \\
\hline \multicolumn{2}{|l|}{ Sharing via social media } \\
\hline Permissions sought & $\begin{array}{l}\text { Does the app ask for push } \\
\text { notifications or terms \& } \\
\text { conditions etc.? }\end{array}$ \\
\hline \multicolumn{2}{|l|}{ Ease of use } \\
\hline Updates & $\begin{array}{l}\text { How easily it updates, how } \\
\text { often and what types }\end{array}$ \\
\hline Sponsorship information & \\
\hline
\end{tabular}


have been posted by developers competing for business (Bertolucci, 2009).

Two focus groups were conducted. The first consisted of UK music festival attendees who had experience of using a festival app, and the second consisting of UK music festival attendees who had yet to use an app. Focus groups were useful given the experiential nature of the knowledge being researched and their suitability when little is known about the topic (Stewart, Shamdasani, \& Rook, 2007). Focus groups are also useful for idea generation (Yeoman, Robertson, Ali-Knight, Drummond, \& McMahonBeattie, 2004). The focus groups solicited "expert" opinion, with participants chosen based on their festival experience and knowledge rather than for representation purposes. Participants were recruited using a snowball strategy that, given the relative "youth" of the technology, led to recommendations of app users and participants with a shared "trait" who were willing to discuss their experiences under the study conditions. Given the study focus, the group composition was predominantly 21-24 year olds. Each focus group consisted of six participants, which is ideal to generate discussion (Rio-Roberts, 2011).

The secondary data analysis informed the focus group protocol. This consisted of a skeleton of open-ended questions (type II questions), which aim to start discussion and seek opinions, followed by more specific prompts (type I questions) (De Wever, Schellens, Valcke, \& Van Kerr, 2006). The protocol also included "focusing exercises" to draw participants' attention to particular topics and to provide some interactivity in order to maintain their full attention throughout (Bloor, Frankland, Thomas, \& Robson, 2001). For example, participants were asked to rank different features of the apps. The focus groups were audio recorded with an assistant scribe taking additional notes. The audio recording was transcribed soon after, with the assistance of the scribes' notes to ensure clarity of the information (Simon, 1999). A process of open coding was used to develop analytical themes.

Findings and Analysis

\section{Practicalities of Smartphones at Music Festivals}

The festival experience brings to the fore a number of practical concerns with smartphone use.
Smartphones represent a relatively expensive item for the majority of the population, especially the youth market that attends festivals. This leads to user-centered concerns with respect to the loss or damage of smartphones. For example:

I wouldn't trust myself to take a Smartphone to a festival because I'd probably lose it. (Lucia, FG1)

I probably wouldn't take my Smartphone just in case I lose it or break it. (Jane, FG2)

The crowded festival environment together with alcohol intoxication could heighten the real as well as perceived potential for loss with a subsequent impact on the festival experience.

A second practical concern was the relatively short battery life of smartphones together with the tendency of apps to prolong smartphone use and drain batteries more rapidly. This presents a problem for both users and organizers because most active users require charging facilities every day. In addition, social networking and location-based services tend to place a higher demand on batteries and account for around $50 \%$ of battery drain ("Motorola Droid," 2012). Given these are core features of many festival apps, organizers and sponsors are recognizing and responding to this need and in some instances integrate battery charging with sponsorship opportunities. For example:

I remember at Glastonbury, there was an Orange Mobile tent which you could charge your phones at. (Francesca, FG1)

Francesca's recall of Orange Mobile shows the efficiency of this sponsorship opportunity. In this instance, the sponsorship provided utilities free of charge to all attendees. Other festivals provide similar services but tend to charge a small fee. For example, at Download Festival, Vodafone offered their customers free charging whereas other networks were required to pay a small fee, and at Reading all attendees were required to pay the fee. This resulted in a less memorable experience as Francesca did not recall these tents and Kim felt it was not worth the small fee. There was consensus that battery life was a weakness for festival apps and could have a detrimental effect on app usage. Participants would be more likely to use an app and 
more of its features if mobile charging was available free of charge. It is also evident that the differential charging policy applied by Vodafone conflicts with the egalitarianism and communitas associated with festivals (Getz, 2007).

As a result of both battery life and concerns over smartphone loss, many users choose not to take smartphones to festivals. Analysis of festival forums indicated that some smartphone users choose to keep an older, cheaper mobile, which is adequate for their festival needs and has an interchangeable battery option.

A third practical concern relates to signal strength, which can be especially poor at rural festivals. Apps incorporating social media or mapping software require a good $3 \mathrm{G}$ signal or Wi-Fi to run at an optimal level. For instance, the Download Festival and Isle of Wright Festival apps include a tent pinning feature to enable festival goes to locate their tents. While the GPS location will operate without a phone signal, users need 3G to run the map in the background to usefully orientate themselves. 3G or Wi-Fi is also needed to download apps for the first use.

\section{Preevent Experience}

As per the five-stage recreation model suggested by Clawson and Knetsch (1966), a festival is a "multiphased" experience (Berridge, 2007) beginning with anticipation of the event. The use of the app during this phase was prominent in the discussion and identified as the most important feature during a focus group activity (Table 4). For example:

I would probably download the app, but before I go as an organization and hype kinda thing. (Neil, FG2)

Another participant (Brad) articulated his preevent usage as information searching and stated the app was "a nice alternative to looking on the website," illustrating the trend to use native apps over websites (Fisher, 2012). All focus group participants used apps for prefestival information searching, with some using the app exclusively at this stage, demonstrating the importance in prefestival preparation. Apps therefore need to meet consumer needs at this key event experience stage to ensure continued usage and create positive momentum prior to the festival.
Table 4

App Features Ranked by Focus Group Participants

\begin{tabular}{ll}
\hline Feature & \multicolumn{2}{c}{ Importance } \\
\hline Preevent information & Most important \\
Regular updates & \\
Usability & \\
Location services & \\
Personalization & \\
Interactivity & \\
Deals \& discounts & \\
News & \\
Stalls advice & \\
Looks & \\
Social media & \\
Postevent information & \\
Sponsors information & Least important \\
Instructions on how to use the app &
\end{tabular}

Participants were also keen to see travel information within apps. While some details are currently available, more were sought. However, this is a significant undertaking and overly optimistic at the present time, especially as users anticipate real-time travel information updates. While this would assist with the second phase of the multiphase experience, which is travel to the event, users are best guided to specialized travel apps that will better meet their needs. However, given that some apps integrate an element of social networking, it might be worthwhile including a travel posts section so users can provide live updates about travel problems. This web 2.0 feature has been acknowledged as a useful feature for travel communities (Dickinson et al., 2012). In addition, festival manages might consider providing live travel updates regarding travel problems in the immediate vicinity of the festival, though to be useful this would require constant updates.

Analysis of app store reviews also indicates the preevent phase needs a stronger focus as users' expectations were not always met. For instance, significant value was attributed to scheduling features, with many festival apps causing disappointment. For example, V Festival and T in the Park did not provide timings of bands and Reading Festival charged attendees $£ 10$ for these scheduling privileges. Some attendees even reported a technical fault after they had paid, with one user stating that:

This actually put a downer on my festival and made me physically angry! (Reading, iTunes) 
This demonstrates the impact on emotions that lie at the heart of all consumption experiences (Carù \& Cova, 2003). Download Festival and Isle of Wight Festival embedded scheduling in their respective apps and this resulted in a high level of five-star ratings and positive reviews:

This was a great addition to the festival, especially being able to create your own schedule. Great to glance at for quick reminders. (Isle of Wight Festival, iTunes)

Good app, very helpful especially for band times. Hope it gets updated or recreated for next year. (Isle of Wight Festival, Google Play store)

Was fab for band schedules. Didn't miss anyone we wanted to see. (Download Festival, iTunes)

\section{The (Un)Structured Event Experience}

Scheduling is an important feature both before and during the event where it helps users achieve competence and control (Hemmerling, 1997, cited in Bowdin et al., 2011). On the other hand, concerns were raised during the focus group with regarding the ability to schedule. For example:

If you try and schedule your festival experience too much you lose a lot of the experience I think a lot of it you just stroll across a tent and think oh that sounds good so you just go in on a whim, rather than just saying I should be here and here, it would just feel a bit like being at home. (Kim, FG1)

Kim highlights a conflict between the competence and control achieved through scheduling and the view that the "experience should be unstructured" (Getz, 2007, p. 178), reflecting Kim’s impromptu choices made when "strolling across" a tent that she likes. By planning ahead Kim feels she is echoing everyday life and therefore engaging in a utilitarian style of consumption, which Li, Dong, and Chen (2012) found to have a negative effect. Similarly Brad demonstrates just how the app could affect the festival experience in a negative way.

A potential weakness as well, talking about the experience, if apps get really popular and everyone ends up having an app on their Smartphone and taking their Smartphones to the festivals, it's going to turn into everyone just wandering around on their Smartphones the whole time, like you won't actually be experiencing the festival. (Brad, FG1)

If everyone is on the app, the whole festival experience will not be engaging the consumer as it would disrupt the goal direction. Though the wholesale abandonment of the sense of freedom experienced at a festival is unlikely, this does indicate a degree of balance is needed. Some competence and control is vital, and this will vary between individual users, but spontaneity remains important. Apps have good capacity to reveal the unexpected through push notifications and can deliver a highly personalized experience through context awareness. This can offer users a more hedonic feel. It is, however, clear that an app that disrupts attendee engagement will impact on the cocreation of unique value (Prahalad \& Ramaswamy, 2004). For instance, an app that demands constant attention would reduce immersion within the experience.

Despite these concerns, competence and control appeared to be a high need. Examples of this include: use prior to the festival in order to be fully prepared; checking the line-up; and desire for more detailed features such as better festival site maps. In the ranking task, regular updates were the second most important feature (Table 4). For some participants, this was their rationale for app usage with live updates a highly desirable feature. Participants also recognized how this could alter their event experience in a positive manner.

Regular updates would be really useful, a couple of times at Reading I missed the start of a band I really wanted to see because I was seeing a "filler" band while I was waiting and the times had been changed slightly so I was pretty annoyed as I'd been waiting to see the bands all weekend and I heard what I missed was awesome. (Alan, FG2)

This ability to master the spatial and temporal fluctuations of an event is a novel feature that an app can deliver in a personalized form (e.g., linked to the user's location, preferences, or schedule), which promises a more positive event experience through providing easy access to information that can prevent negative experiences from occurring. 
However, these updates are currently posted within the news section of apps resulting in longer app usage as users have to look for information. Participants agreed that an improvement on this service would be push notifications with the desired information select in the app settings.

The time spent using an app was a focus of discussion with usability ranked fourth (Table 4). An app that was difficult to use or slow would be deleted.

If it's difficult to use or annoying I just wouldn’t use it. (Tony, FG1)

I put usability first because like, regardless of anything else if it's not a usable app then it's pointless, if it's not really easy to use it's annoying. (Alan, FG2)

I put usability second as it's quite important that you could find your way around the app relatively easy rather than sitting there for ages trying to find stuff. (Diane, FG2)

Top of mine is usability if I can't use it I'm going to delete it straight away. (Brad, FG1)

The user interface needs to be created for the user's limited attention (Y. E. Lee \& Benbasat, 2004), which is likely to be very restricted in a festival context and impede convenience (Liu, 2010; Ting et al., 2011; Wagner, 2011). Analysis of app reviews shows attendees are noticing comparative weaknesses. For instance, one of the Isle of Wight reviews stated: "Bestival take note" (User 6, Isle of Wight iTunes).

Usability is also measured through the information and features provided within the app. Contrary to the event anticipation phase, the general consensus was that only basic information was necessary in the app during the event experience. Two essential features stand out: a map that goes more in-depth than the program, featuring more details on toilets, food stalls, and bars; and the schedule.

I look for apps that just give information, I just want basics. (Brad, FG1)

I'd download it for the basic things like mapping things and personalizing the schedule I can't be bothered messing about with other stuff. (Mark, FG2)
The prominent explanation for this discrepancy revolved around the security issues regarding having the smartphone in view for long periods of time and the "state of mind" at festivals requiring quick access to information. User attention needs to be minimal to avoid impeding on immersion in the festival experience. Any disruption affects "flow" (Csikszentmihalyi, 1990) as an app could heighten psychic entropy felt by the consumer as it presents random information interference. On the other hand, a skilled smartphone user can view the app as a tool and utilize their skills to deal with challenges, such as band clashes, and through this mastery achieve "flow." An appropriate scheduling tool would enable users to set "rules," for example, prioritizing seeing a favorite band's whole performance. To some extent this also helps the user "step out of time" since the app takes control of the scheduling rather than the participant relying on clock time and all the attendant vagaries of scheduled changes at a music festival. Therefore, though the user is effectively sticking to their schedule, as described earlier by Kim, they do so without having to clock watch and check details. However, for this to work effectively the app would need to embed live updates into the scheduling tool and operate with a high degree of reliability. This is often absent from current apps given the rush by festival organizers and developers to release apps that have probably not been rigorously tested. Live updates also place a high demand on app developers and festival organizers.

\section{Presence}

The personalization of schedules is a sought after feature that improved the app experience and can be examined through the lens of presence theory (Venkatesh et al., 2003). Presence is meant to combine sensory and cognitive inputs in order to result in a "more engaging user experience" (K. M. Lee et al., 2010, p. 273). Analysis suggests presence in a festival app can be achieved through meeting functional and emotional needs. For instance, functional needs are enhanced by a personalized app interface that requires less user attention, vital in the festival context. Emotional needs are met through engagement with the consumer in a personal manner, a key feature of memorable experiences (Pine \& Gilmore, 
1999). For example: "Gave me the feeling of customizing my own festival” (Mark, FG2).

As Mark implies, this customization gives a feeling of ownership of the festival experience. As well as personalized schedules, apps offer GPS location services. Currently the most advanced apps allow pinning of favorite locations in order to orientate users relative to their current location. Increasingly more sophisticated location services are evolving (K. M. Lee et al., 2010) to enhance presence through route planning based on user needs. In a festival context this might be a route that takes in a user's favorite food stall prior to seeing a certain band. However, GPS use impacts on battery life and charging facilities would be a necessity for mobile users running GPS in the background. Route specification could also conflict with hedonic experience seeking, as discussed above.

A further feature known to enhance presence is social media, though this also makes demands on battery life. Given the availability of independent social networking apps such as Facebook and Twitter, participants did not generally appreciate this as a festival app function, although there was discussion of users who might. However, this is a gray area as discussion indicated the desirability of setting up a personalized social network of users all attending the festival. Features such as the ability to locate and message a group of selected friends were particularly attractive, especially if a user was to get lost. For example:

One of the years I went to Reading I lost people for like 2 hours. I'd like to be able to say “hey I'm here" so they'd be able to find me. Whereas I had to walk all the way back to the campsite which was like a half hour walk, and then they weren’t there, then had to walk half an hour back and just sat on my own for half an hour. (Lucia, FG1)

Personalizing it so that you can tag yourself and only your friends can find out where you were that would be really good. (Elexa, FG2)

There are quite a few issues raised with regards to safety at a festival . . . but if there was some separate kind of personalization with your friends that would be really good. (Jane, FG2)

Apps such as co-mob net (http://www.comob.org. uk/) and 6th Sense (www.sixthsense.com) utilize such features that could be readily adapted to the festival environment. These apps enhance presence through spatial awareness related to people of immediate importance to the user (Nokia Group, 2002). While making significant demands on battery life, spatial awareness of other users would enhance opportunities for cocreation. Sponsorship, conversely, seemed to have a negative impact on the app's presence.

Information about sponsors erm . . . you get enough information throughout the event anyway, do you really want any more? (Elexa, FG2)

I don't like apps with too many adverts and stuff inside. (Alexis, FG1)

As Elexa and Alexis suggest, the festival environment can be dominated by sponsorship. In contrast Bellman, Potter, Treleaven-Hassard, Robinson, and Varan (2011) found a positive correlation between the branding within the apps and consumer engagement; however, their study focused on branded apps, which are used by consumers in other contexts. While sponsors will no doubt see apps as an opportunity, this needs to be approached with care.

\section{Conceptual and Practical Development}

Current evidence suggests growth in app use in general and a growing number of music festivals developing apps. Overall, the use of apps during the festival experience has the potential to change the practices of festival participants and this requires a rethink of some of the experiential literature. Two elements are considered here. Within the festival environment an app provides users with new skills to cocreate the experience through the ubiquity of smartphone technology. This will have most impact on elements of the experience related to structure, such as spontaneity, effectively providing a tool for mastery of space-time coordination within the festival confines and also external to the festival. The experiential literature therefore needs to consider the "relativity" of the experience as apps provide users with sensitivity to their "place" in relation to other people, the event schedule, their spatial location, and the things needed. Context awareness provides new competencies relative to time, as in the 
schedule, space, and people. This builds on what has previously been described as microcoordination (Ling, 2004) in everyday use of mobile technology. In the festival environment this provides the opportunity to micromanage the experience, should the user choose. However, this micromanagement is not necessarily desirable for emersion in the festival experience and inevitably users need options to decide the degree to which they wish to harness the available technology.

The second element of experience modified by festival apps is the engagement with other participants and the emergence of new forms of community. Social media has sparked new interest in the concept of community and research has questioned whether this has eroded traditional placebased community relations by isolating individuals or created new forms of personalized networks (Humphreys, 2010). Festivals are an example of a fluid public-private space where individuals interact across various spatial boundaries and scales of social group both at the festival and with wider social networks beyond the festival site. Festival attendees seek a sense of "communitas" that transcends traditional social barriers. Here White's (1992) concept of "gel” provides a useful metaphor to understand the processes:

Whereas networks connect smaller units into larger entities, and such entities in turn form their own networks which constitute still larger social organizations, a gel is something in which such levels are not distinct. If we understand socialities as always grounded in physical space and time, but in contexts of sheer messiness, we may need to think about social life in nonnetwork terms. (Sheller, 2004, p. 47).

Mobile communication enables festival participants to move in and out of different social settings and mediates the festival experience in a variety of social contexts decoupled from spatial and temporal boundaries. Thus, participants can manage their sociality with those in their immediate spatial presence, others at the festival to which they wish to remain connected, and wider groups beyond the festival site where they may be engaged in other ongoing storylines.

On a practical level, with the emergence of new forms of community and network sociality
(Humphreys, 2010; Sheller, 2004; Wittel, 2001), festival attendees will be used to managing the relational capabilities of smartphones. With increasingly competent users of technology, used to wellestablished and robust apps, users will have high expectations. Key areas that app developers and festival organizers need to focus on are the preevent app usage, festival schedules, and personalization options.

\section{Conclusion}

Smartphone apps are increasingly utilized in the festival domain and bring new challenges for festival organizers in managing the festival experience. Apps have the potential to alter the user experience of music festivals, particularly since the festival market attracts attendees who are more likely to be skilled users of smartphones keen to utilize the technology. The technology in this field is evolving rapidly and the current festival apps will change year to year as lessons are learnt from practical application in the field. As with other forms of mobile and social media, much will be learned from user application of the technology, and this does not necessarily match the expectations of developers. Research in this field is in its infancy and event organizers have yet to fully grasp the implications of technology for the event experience.

Analysis of current apps and festival goers' experiences of these apps indicates that app designers need to focus on the whole festival experience, especially the event anticipation phase as well as the on-site experience. There is a functional need for improved scheduling and live updates to make apps valuable tools while immersed in the festival experience. At present only two out of the nine apps reviewed currently provide a satisfactory level of service throughout the whole experience. Festival apps therefore need to acquire a more "consumer centric approach" (Venkatesh et al., 2003). Currently, while the apps help enhance the festival experience through providing the consumer with more "competence and control” (Getz, 2007, p. 172) and assist in finding services, there are concerns that apps could, in the future, impede the festival experience as people become more immersed in the app and their smartphones. Importance is placed on the "communitas" (Getz, 2007) and "escapist” (Pine \& Gilmore, 1999) 
experience within the festival, and participants felt that the app could threaten this.

At a conceptual level, apps bring a new "relativity" to the festival experience as users are able to visualize themselves in relation to key people, the event schedule, their location, and personal needs. This provides users with tools to micromanage the experience. Apps also extend opportunities for network sociality both within and outside the festival confines through the creation of personalized networks providing a medium that transcends spatial boundaries and enhances the sense of connectivity.

Given that apps are a relatively new tool, that first emerged on the festival scene in 2010, the conclusions of this study can only be considered preliminary. Further research is needed in three respects. First, we need better understanding of user needs in an event context and, second, we need to observe how users adapt apps to suit their needs. Studies elsewhere show how end users do unexpected and unintended things with technology, for better or for worse (Couclelis, 2009). This might be best gleaned from ethnographic work that understands the use context. Third, this understanding needs to feed into a better conceptual understanding of the event experience that will evolve alongside technological capabilities.

\section{References}

Adema, K. L., \& Roehl, W. S. (2010). Environmental scanning the future of event design. International Journal of Hospitality Management, 29(2), 199-207.

Allen, J., O’Toole, W., Harris, R., \& McDonnell, I. (2011). Festival \& special event management (5th ed.) Milton: John Wiley \& Sons Australia Ltd.

App happy. (2011). Corporate Meetings \& Incentives, 30(2), $16-23$.

Bellman, S., Potter, S. F., Treleaven-Hassard, S., Robinson, J. A., \& Varan, D. (2011). The effectiveness of branded mobile phone apps. Journal of Interactive Marketing, 25(4), 191-200.

Berridge, G. (2007). Events design and experience. Burlington: Elsevier.

Bertolucci, J. (2009). Can you trust iTunes app store reviews? PC World, 27(6), 25-26.

Bloor, M., Frankland, J., Thomas, M., \& Robson, K. (2001). Focus groups in social research. London: Sage.

Bowdin, G., Allen, J., O’Toole, W., Harris, R., \& McDonnell, I. (2011). Events management. Oxford: ButterworthHeinemann.

Buhalis, D., \& Law, R. (2008). Progress in information technology and tourism management: 20 years on and 10 years after the Internet-The state of eTourism research. Tourism Management, 29, 609-623.

Business Insider. (2012). HTML5 will replace native appsbut it will take longer than you think. Retrieved from http://articles.businessinsider.com/2012-01-09/tech/ 30606532_1_android-app-store-html5

Campbell, S. W., \& Kwak, N. (2011). Mobile communication and civil society: Linking patterns and places of use to engagement with others in public. Human Communication Research, 37, 207-222.

Carù, A., \& Cova, B. (2003). Revisiting consumption experience: A more humble but complete view of the concept. Marketing Theory, 3(2), 267-286.

Chang, T-Y., \& Horng, S-C. (2010). Conceptualizing and measuring experience quality: The customer's perspective. Service Industries Journal, 30(14), 2401-2419.

Clawson, M., \& Knetsch, J. L. (1966). Economics of outdoor education. Baltimore: The Johns Hopkins University Press.

Couclelis, H. (2009). Rethinking time geography in the information age. Environment and Planning A, 41, 1556-1575.

Counts, S., \& Fellheimer, E. (2004). Supporting social presence through lightweight photo sharing on and off the desktop. In Proceedings of ACM CHI 2004 Conference on Human Factors in Computing Systems, April 24-29 Vienna, Austria. Retrieved from http://research.microsoft.com/pubs/69311/photo_sharing_chi04.pdf

Csikszentmihalyi, M. (1990). Flow. New York: Harper \& Row.

De Wever, B., Schellens, T., Valcke, M. \& Van Keer, H. (2006). Content analysis schemes to analyze transcripts of online asynchrononous discussion groups: A review. Computers \& Education, 46(1), 6-28.

Dickinson, J. E., Ghali, K., Cherrett, T., Speed, C., Davies, N., \& Norgate, S. (2012). Tourism and the smartphone app: Capabilities, emerging practice and scope in the travel domain. Current Issues in Tourism, 17(1), 84-101.

Dietz, C. (2011, June 1). Roaming empire: The rise of the event app. Event, 16-17.

Driver, C., \& Clarke, S. (2008). An application framework for mobile, context-aware trails. Pervasive and Mobile Computing, 4(5), 719-736.

Duffy, M. (2005). Performing identity within a multicultural framework. Social \& Cultural Geography, 6(5), 677-692.

Fisher, D. (2012). Websites are being replaced. ABA Banking Journal, 104(1), 21-25.

Forsyth, E. (2011). Ar u feeling appy? Augmented reality, apps and mobile access to local studies information. Australasian Public Libraries and Information Services, 24(3), 125-132.

Frommer's Unlimited. (2011). Digital travel content and user experience survey. London: Frommers.biz.

Getz, D. (2007). Event studies: Theory, research and policy for planned events. Oxon: Elsevier.

Giaglis, G. M., Kourouthanassis, P., \& Tsamakos, A. (2003). Towards a classification framework for mobile location services. In B. E. Mennecke \& T. J. Strader (Eds.), Mobile commerce: Technology, theory, and applications (pp. 67-85). Hershey: Idea Group Publishing. 
Humphreys, L. (2010). Mobile social networks and urban public space. New Media and Society, 12(5), 763-778.

Jensen, R. (1999). Dream society: How the coming shift from information to imagination will transform your business. New York: McGraw-Hill.

Jiang, L. C., Bazarova, N. N., \& Hancock, J. T. (2010). The disclosure-intimacy in computer-mediated communication: An attributional extension of the hyperpersonal model. Human Communication Research, 37, 58-77.

King, R. C., \& Xia, W. D. (1997). Media appropriateness: Effects of experience on communication media choice. Decision Sciences, 28(4), 877-910.

Korkmaz, B., Lee, R., \& Park, I. (2011). How new Internet standards will finally deliver a mobile revolution. McKinsey Quarterly, 3, 46-53.

Kwan, M.-P. (2007) Mobile communications, social networks, and urban travel: Hypertext as a new metaphor for conceptualizing spatial interaction. The Professional Geographer, 59(4), 434-446.

Lee, K. M., Yates, D., Clark, J., \& El Sawy, O. (2010). Value creation of mobile services through presence: Designing mobile information and entertainment applications with presence in mind. Presence-Teleoperators and Virtual Environments, 19(3), 265-279.

Lee, Y. E., \& Benbasat, I. (2004). A framework for the study of customer interface design for mobile commerce. International Journal of Electronic Commerce, 8(3), 79-102.

Li, M., Dong, Z. Y., \& Chen, X. (2012). Factors influencing consumption experience of mobile commerce: A study from experiential view. Internet Research, 22(2), 120-141.

Line, T., Jain, J., \& Lyons, G. (2011). The role of ICTs in everyday mobile lives. Journal of Transport Geography, 19(6), 1490-1499.

Ling, R. (2004). The mobile connection: The cell phone's impact on society. San Francisco: Morgan Kaufmann.

Liu, C. C. (2010). Measuring and prioritising value of mobile phone usage. International Journal of Mobile Communications, 8(1), 41-52.

Matheson, C. M. (2005). Festivity and sociability: A study of a Celtic music festival. Tourism Culture \& Communication, 5(3), 149-163.

Mintel Reports. (2011). Mobile phone apps-UK-June 2011. London: Mintel Group Ltd.

Mintel Reports. (2014). Digital trends autumn-UK-September 2014. London: Mintel Group Ltd.

mobiThinking. (2012). Global mobile statistics 2012 Part A: Mobile subscribers; handset market share; mobile operators. Retrieved from http://mobiforge.com/researchanalysis/global-mobile-statistics-2014-part-a-mobilesubscribers-handset-market-share-mobile-operators

Morgan, M. (2007). What makes a good festival? Understanding the visitor experience. Event Management, 12(2), 82-93.

Mossberg, L. (2007). A marketing approach to the tourist experience. Scandinavian Journal of Hospitality \& Tourism, 7(1), 59-74.
Motorola Droid RAZR Maxx: Buy it for its improved battery or 10 ways to boost battery life of your existing smartphone. (2012, January). International Business Times.

Murphy, T. (2011). App vs. website. Bank Technology News, 24(6), 39.

Music festivals to expand use of interactive mobile services. (2007, May 17). New Media Age, p. 4.

Neutens, T., Schwanen, T., \& Witloz, F. (2011). The prism of everyday life: Towards a new research agenda for time geography. Transport Reviews, 31(1), 25-47.

Nokia Group. (2002). Staying in touch with presence. Finland: Author.

Packer, J., \& Ballantyne, J. (2005). The impact of music festival attendance on young people's psychological and social well-being. Psychology of Music, 39(2), 164-181.

Pegg, S., \& Patterson, I. (2010). Rethinking music festivals as a staged event. Journal of Convention \& Event Tourism, 11(2), 85-99.

Pessin, A. (2011). Smartphone mobile apps as key campaign driver for 2012. Campaigns \& Elections, 32(304), 11-12.

Pine, J., \& Gilmore, J. H. (1999). The experience economy. Boston: Harvard Business School Press.

Prahalad, C. K., \& Ramaswamy, V. (2004). The future of competition: Co-creating unique value with customers. Boston: Harvard Business School Press.

Rio-Roberts, M. D. (2011). How I learned to conduct focus groups. The Qualitative Report, 16(1), 312-315.

Schwanen, T., \& Kwanm, M. P. (2008). The Internet, mobile phone and space-time constraints. Geoforum, 39, 1362-1377.

Shapiro, M. J. (2011). Update: Apps for meetings. Meetings \& Conventions, 46(8), 31-36.

Sheller, M. (2004). Mobile publics: Beyond the network perspective. Environment and Planning D: Society and Space, 22, 39-52.

Simon, J. (1999). How to conduct focus groups. Nonprofit World, 17(5), 40-43.

Smith, S., \& Grubb, J. (2004). Location and presence in mobile data services. Boxes and arrows. Retrieved from http://boxesandarrows.com/location-and-presence-inmobile-data-services/

Stewart, D. W., Shamdasani, P. N., \& Rook, D. W. (2007). Focus groups theory and practice. Thousand Oaks, CA: Sage.

Thomas, T. (2011). Five technologies event planners can't live without. Successful Meetings, 60(11), 14-16.

Ting, D. H., Lim, S. F., Pantamacia, T. S., Low, C. G., \& Ker, G. C. (2011). Dependency on the Smartphone and the impact on purchase behaviour. Young Consumers, 12(3), 193-203.

United States Government Accountability Office. (2012). Mobile device location data. Retrieved from http://www. gao.gov/assets/650/648044.pdf

Venkatesh, V., Ramesh, V., \& Massey, A. P. (2003). Understanding usability: In mobile commerce. Communications of the ACM, 46(12), 53-56.

Wagner, J. (2011). Anytime/anywhere-Playing catch up with the mind of the Smartphone consumer. International Journal of Mobile Marketing, 6(1), 28-53. 
Wajcman, J. (2008). Life in the fast lane? Towards a sociology of technology and time. The British Journal of Sociology, 59(1) 59-77.

White, H. (1992). Identity and control: A structural theory of social action. Princeton, NJ: Princeton University Press.

Wilken, R. (2008). Mobilizing place: Mobile media, peripatetics, and the renegotiation of urban places. Journal of Urban technology, 15(3), 39-55.
Wittel, A. (2001). Toward a network sociality. Theory, Culture \& Society, 18(6), 51-76.

Yeoman, I., Robertson, M., Ali-Knight, J., Drummond, S., \& McMahon-Beattie, U. (2004). Festival and events management: An international arts and culture perspective. Burlington: Elsevier. 